\title{
Successful treatment of lichen planus with sulfasalazine in 20 patients
}

A. Bauzá, MD, A. España, MD, P. Gil, MD, P. Lloret, MD, and F. J. Vázquez Doval, MD

From the Department of Dermatology, University Clinic of Navarra, Pamplona, Spain

Correspondence:

Agustín España, MD

Department of Dermatology

University Clinic of Navarra

PO Box 4209 Pamplona 31080 Spain

E-mail: aespana@unav.es

\begin{abstract}
Background

Lichen planus (LP) is a disturbing pruritic cutaneous disease that may have an spontaneous resolution or exhibit a more chronic course during some weeks or months.
\end{abstract}

\section{Objective}

Our objective was to demonstrate that sulfasalazine is effective in the treatment of LP.

\section{Methods}

Twenty patients were diagnosed in our department with LP of the skin and/or mucosa between 1985 and 2001 on the basis of clinical and histologic findings.

\section{Results}

All patients were treated with sulfasalzine at initial doses of $1.5 \mathrm{~g} /$ day, increasing by 0.5 $\mathrm{g} /$ week to $3 \mathrm{~g} /$ day for 4-16 weeks. Some patients also received descendent doses for 2-12 months. Complete responses were observed in 13 patients and partial responses in seven patients. All patients reported an early resolution of the pruritus. No changes were detected in mucosal LP. Most of the patients tolerated the treatment well and only eight patients presented some minor side-effects.

\section{Conclusion}

Sulfasalazine is a successful therapeutic option for cutaneous LP, constituting an alternative to corticosteroids and retinoids. 
Lichen planus (LP) is a common pruritic papulosquamous disorder of unknown origin affecting the skin and/or mucosa. Many drugs such as topical or systemic corticosteroids, retinoids or cyclosporinee are commonly used to treat the skin lesions, showing varying degrees of efficacy and side-effects. ${ }^{1}$

Sulfasalazine and the new aminosalicylates are drugs extensively used in inflammatory bowel disease. They are also an effective second-line therapy for rheumatoid arthritis. It is known that 5-aminosalicylic acid (5-ASA) is the therapeutically active fragment of sulfasalazine (sulfapyridine plus 5-ASA) and it has been observed that it may act, in part, by normalizing dysregulated arachidonic acid metabolism, especially by blocking the increased activity of the 5-lipo-oxygenase pathway and reducing the expression of some adhesion molecules and the number of intraepidermal and dermal $\mathrm{T}$ lymphocytes. ${ }^{2}$ This effect has shown to be of benefit in some dermatoses such as psoriasis. ${ }^{3}$ After a personal observation of the clinical improvement of cutaneous LP in a patient affected with inflammatory bowel disease treated with sulfasalazine, we decided to perform a prospective study including some patients affected with this disease. This is the first report of the successful response of sulfasalazine for the treatment of 20 patients affected with cutaneous LP.

\section{PATIENTS AND METHODS}

Twenty patients were diagnosed in our department with LP of the skin and/or mucosa between 1985 and 2001 on the basis of clinical and histologic findings (Table 1). All patients were included in a prospective study about the efficacy of the treatment with sulfasalazine. None of these patients received additional treatment while under sulfasalazine treatment. A partial response (PR) was considered when $50 \%$ or more of the cutaneous lesions cleared and pruritus ceased. Complete response (CR) was defined as the disappearance of pruritus and $100 \%$ cutaneous lesions on clinical examination, leaving only a residual hyperpigmentation. Patients were examined after the first 4 weeks and every 2 months while under treatment. A blood cell count and liver function tests were performed each visit. After the study, some patients kept us informed of their situation by phone.

\section{RESULTS}

Twenty patients affected with LP were treated with sulfasalazine for a period of 4 weeks to 14 months. The group was composed of 11 males and nine females aged between 5 and 65 years (mean age 41 years). The time of disease ranged from 2 weeks to 16 years (mean time 23 months and a half ). Ten patients had been treated beforehand with local or systemic corticosteroids or retinoids without any successful response. All patients were treated with sulfasalazine at initial doses of $1.5 \mathrm{~g} /$ day increasing $0.5 \mathrm{~g}$ per week until 3 g/day for a period of 4-16 weeks. After the first 4-16 weeks, 11 patients also received decreasing doses of sulfasalazine from $3 \mathrm{~g} /$ day to $1 \mathrm{~g}$ /day for 2-12 months, reducing 0.5 $\mathrm{g} /$ day every 2 or 4 weeks depending on the clinical response. Seven patients only received the initial increasing doses: four patients abandoned treatment because of adverse effects and the other three did not want to continue treatment after achieving a CR. The only child in the study received lower doses of $1 \mathrm{~g}$ /day maintained for 16 weeks followed by a further 12 weeks of $1.25 \mathrm{~g} /$ day. This patient and patient 17 are still under treatment with sulfasalazine (Table 1). 
All patients experienced major improvement of their cutaneous lesions and reported an early resolution of the pruritus after 5-7 days. The final assessment of response, referred only to cutaneous LP and not to mucosal LP, was made when the patients obtained a CR or stopped the treatment. In patients 17 and 20, the assessment of response was made in the last visit. Complete response was obtained in 13 patients after at least 16 weeks of treatment. Partial response was observed in seven patients after at least 4 weeks of treatment (Fig. 1). No improvement was observed in the mucosal lesions in any patient. When treatment was discontinued, 10 patients experienced a relapse with a latency of 2 weeks to 6 years. Five patients received further treatment with sulfasalazine after the relapse, and except for one patient who abandoned the treatment because of adverse effects, a CR was obtained in all of them (Table 1).

Most of the patients tolerated the treatment well and only eight patients presented some minor side-effects, such as dyspepsia, skin rash, weakness or headache, which obligated five patients to abandon treatment (Table 1). One of these patients only presented sideeffects when treated with sulfasalazine for a second time. The only child in the study tolerated the treatment well (Fig. 2). No abnormalities were found in the laboratory tests other than a transient leukopenia in one patient who was not present in subsequent tests.

\section{DISCUSSION}

The use of sulfasalazine as treatment for patients with LP has never been previously described. We have demonstrated that oral sulfasalazine administered in increasing doses from 1.5 to $3 \mathrm{~g}$ /day for at least 4 weeks is a useful treatment for cutaneous LP but not for LP of the mucosa. In addition, sulfasalazine also helped in early elimination of the disturbing pruritus associated with LP lesions. Its efficacy was not accompanied by severe side-effects, and when they appeared they were reversible by reducing the dosage or discontinuing use of the drug. It is possible that some patients had a spontaneous remission of the cutaneous lesions during treatment, but the fact that three patients had a relapse only 2 weeks after the treatment was discontinued and that four patients had a good response when sulfasalazine was given for a second time, supports the therapeutic effect of sulfasalazine in cutaneous LP.

We do not know exactly why sulfasalazine is useful in cutaneous LP. In biopsies of LP lesions, large amounts of cytokines have been identified, which are produced by keratinocytes and tissue-infiltrated mononuclear cells. ${ }^{4}$ Some reports have demonstrated raised concentrations of some interleukins (IL) like IL-2, IL-6 and IL-10 in mononuclear infiltrates from oral LP when compared with gingival inflammatory cells. Besides, cells expressing m-RNA for tumor necrosis factor- $\alpha$ (TNF- $\alpha$ ) and tumor growing factor- $\beta_{\mathrm{I}}$ $\left(\mathrm{TGF}-\beta_{\mathrm{I}}\right)$ have been found in biopsies of patients with LP. These results suggest that both pro- and anti-inflammatory cytokines, from T-helper1 and T-helper2 cells, are generated simultaneously in chronic lesions of LP. ${ }^{5}$ Moreover, some adhesion molecules such as vascular cellular adhesion molecule 1 (VCAM-1), intercellular adhesion molecule I $(\text { ICAM-1 })^{6}$ and E-selectin adhesion molecule I (ELAM-1) ${ }^{7}$ are expressed by Langerhans and endothelial cells in oral and cutaneous LP. ${ }^{8}$ Sulfasalazine is able to decrease adhesion molecules (VCAM, ICAM, ELAM) expression by inhibition of nuclear factor- $\kappa \beta(\mathrm{NF}-\kappa \beta)$ transcription in rat cardiac transplants. ${ }^{9}$ This drug also prevents T-helper I cells' immune response by suppressing IL-12 production in macrophages and inhibits lymphocyte proliferative responses and IL-2 production. ${ }^{10}$ Reductions have been observed in ICAM-1 expression, leukotriene (LTB4) synthesis and in the number of intraepidermal and dermal T lymphocytes, as well as T-helper CD4 cells in the skin biopsy of patients affected with 
psoriasis treated with sulfasalazine. ${ }^{2}$ We rather think that, in the same way as in psoriatic patients treated with sulfasalazine, the inhibition of expression of some cytokines and adhesion molecules could play an important role in LP. Nevertheless we do not understand why sulfasalazine is so useful in cutaneous LP but there is no response in the oral lesions. Perhaps cytokine expression is not exactly the same in these two clinical manifestations of the same disease. Further studies are needed to confirm this hypothesis.

Curiously, previous reports had showed the appearance of cutaneous or oral LP as a complication of sulfasalazine therapy in patients with bowel inflammatory disease ${ }^{11}$ and rheumatoid arthritis. ${ }^{12}$

In the light of these findings, we think that sulfasalazine can be regarded as a new therapeutic option in the treatment of cutaneous LP, not only for its efficacy but also because there are no major adverse effects. It thus constitutes an interesting alternative to treatment with systemic corticosteroids or retinoids.

\section{REFERENCES}

1. Daoud MS, Pittelkow MR. Lichen planus. In: Fitzpatrick, Eisen, Wolff, et al., eds Fitzpatrick's Dermatology in General Medicine, 5th edn. EDZ, Vol. 1. McGrawHill, 1999: 561-580.

2. Gupta AK, Ellis CN, Siegel MT, et al. Sulfasalazine improves psoriasis: a doubleblind analysis. Arch Dermatol 1990; 126: 487-493.

3. Gupta AK, Ellis CN, Siegel MT, et al. Sulfasalazine: a potential psoriasis therapy? J Am Acad Dermatol 1989; 20: 797-800.

4. Yamamoto T, Osaki T. Characteristic cytokines generated by keratinocytes and mononuclear infiltrates in oral lichen planus. J Invest Dermatol 1995; 104: 784788.

5. Simark-Mattsson C, Bergenhohz G, Jontell M, et al. Distribution of interleukin-2-410 , tumor necrosis factor-á and transforming growth factor- $\beta$ mRNAs in oral lichen planus. Arch Oral Biol 1999; 44: 499-507.

6. Walton LJ, Thornhill MH, Farthing PM. VCAM-1 and ICAM-1 are expressed by Langerhans cells, macrophages and endothelial cells in oral lichen planus. J Oral Pathol Med 1994; 23: 262-268.

7. Regezi JA, Dekker NP, MacPhail LA, et al. Vascular adhesion molecules in oral lichen planus. Oral Surg Oral Med Oral Pathol Oral Radiol Endod 1996; 81: 682690.

8. Groves RW, Ross EL, Barker JN, et al. Vascular cell adhesion molecule-1: expression in normal and diseased skin and regulation in vivo by interferon gamma. J Am Acad Dermatol 1993; 29: 67-72.

9. Feeley BT, Park AK, Grant Hoyt E, et al. Sulfasalazine inhibits reperfusion injury and prolongs allograft survival in rat cardiac transplants. J Heart Lung Transplant 1999; 18:1088-95.

10. Kang BY, Chung SW, Im S-Y, et al. Sulfasalazine prevents T-helper 1 immune response by suppressing interleukin-12 production in macrophages. Immunology 1999; 98: 98-103.

11. Alstead EM, Wilson AGM, Farthing MJG. Lichen planus and mesalazine. J Clin Gastroenterol 1991; 13: 335-337.

12. Kaplan S, McDonald E, Marino C. Lichen planus in patients with Rheumatoid Arthritis treated with sulphasalazine. J Rheumatol 1995; 22: 191. 

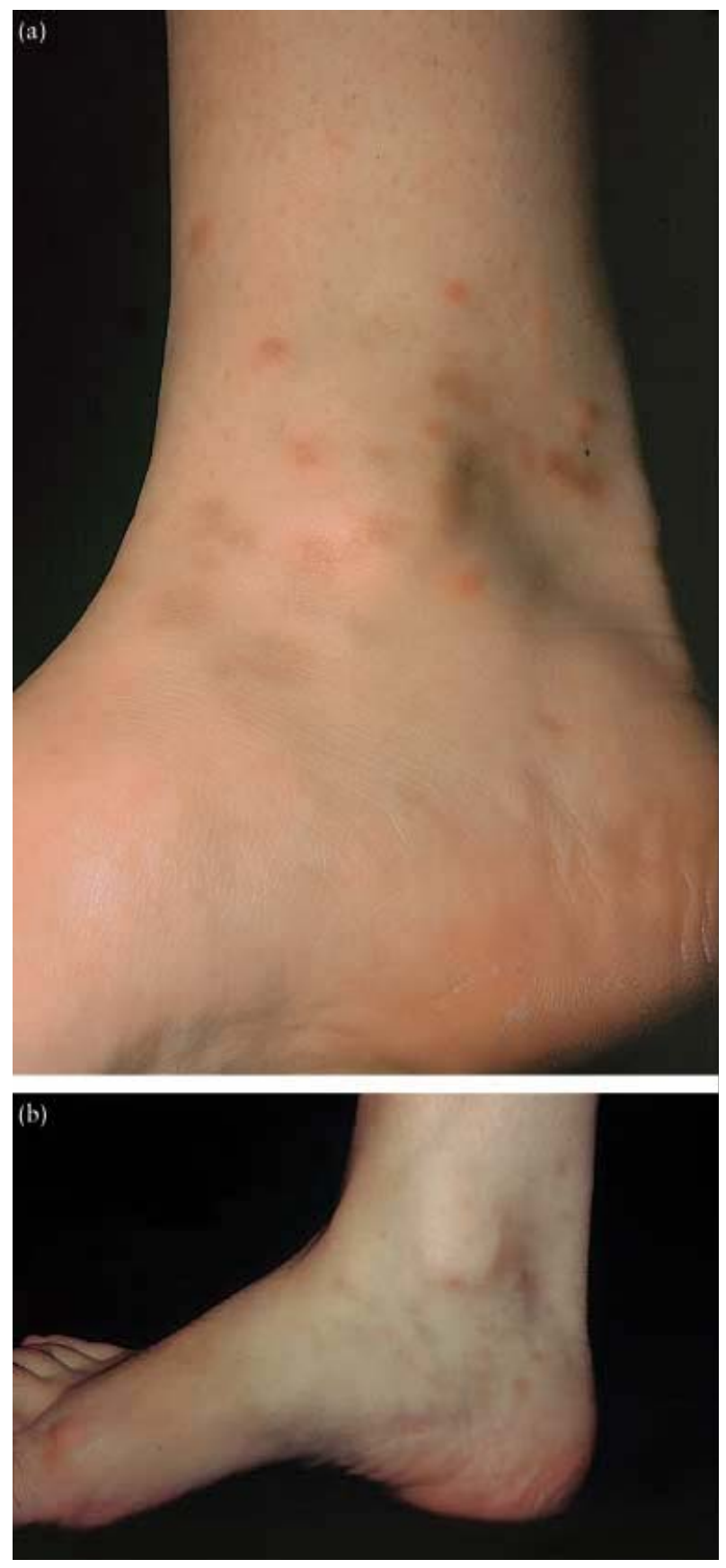

Figure 1. (a) Lichen planus lesions on the feet of patient 11 before treatment with sulfasalazine and (b) the same patient after 9 weeks of treatment, showing a partial response. 

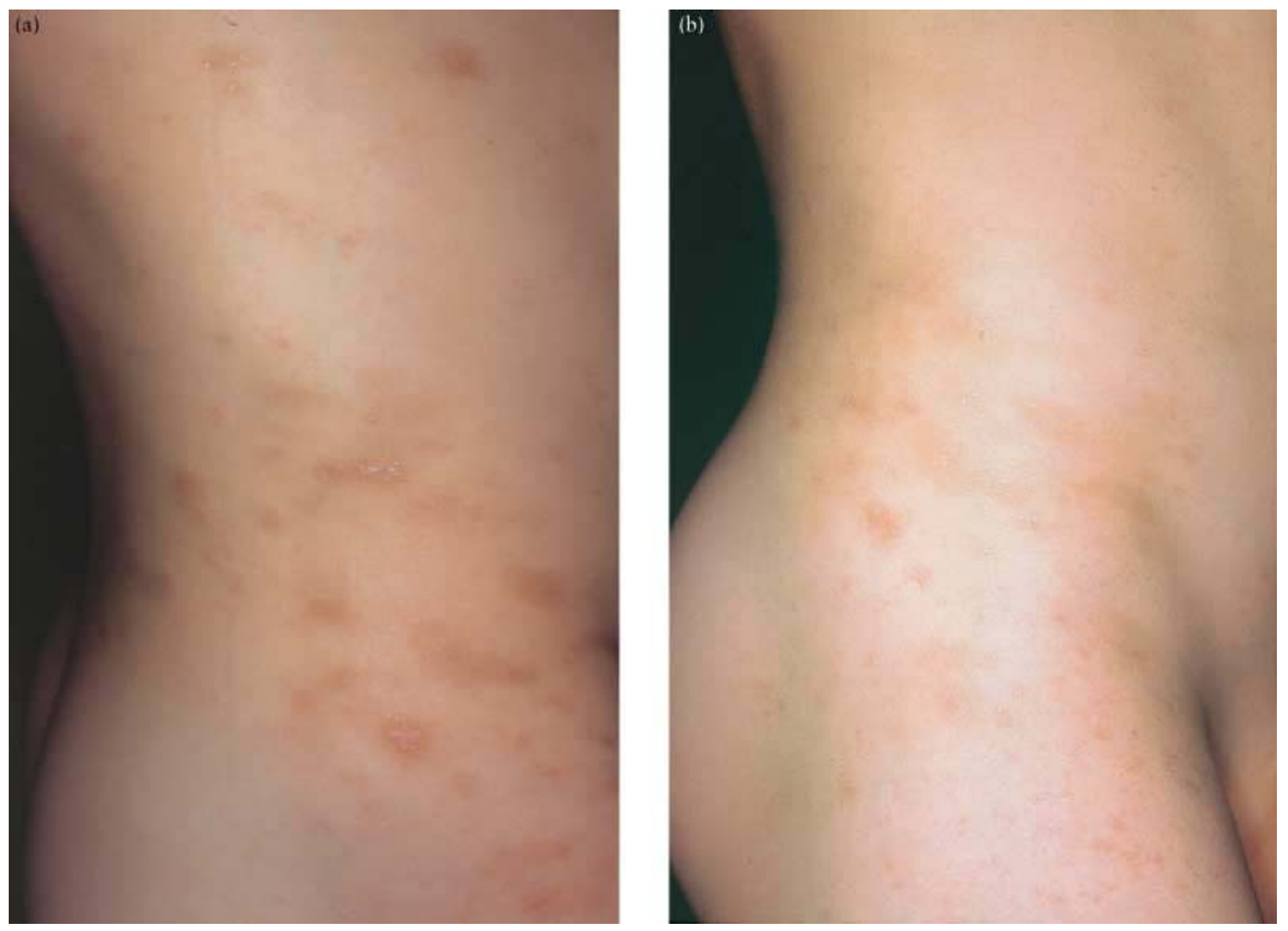

Figure 2. (a) Papulosquamous lesions on the hips of patient 20 before treatment with sulfasalazine and (b) the same patient after 6 weeks of treatment. 
Table 1. Follow up of patients treated with sulfasalazine

\begin{tabular}{|c|c|c|c|c|c|c|c|c|c|c|}
\hline Patient & $\begin{array}{c}\text { Age/ } \\
\text { sex }\end{array}$ & $\begin{array}{l}\text { Time of } \\
\text { illness }\end{array}$ & $\begin{array}{l}\text { Location } \\
\text { of lesions }\end{array}$ & $\begin{array}{c}\text { Time of } \\
\text { treatment dose }\end{array}$ & Response & $\begin{array}{c}\text { Side- effects/time of } \\
\text { appearance }\end{array}$ & $\begin{array}{c}\text { Treatment } \\
\text { abandoned for } \\
\text { adverse effects }\end{array}$ & $\begin{array}{c}\text { Relapse } \\
\text { after treatment/ } \\
\text { time of relapse }\end{array}$ & $\begin{array}{l}\text { New treatment/ } \\
\text { response }\end{array}$ & $\begin{array}{l}\text { Situation at the } \\
\text { end of the study }\end{array}$ \\
\hline 1 & $53 / \mathrm{M}$ & 2 years & $\mathrm{W}, \mathrm{A}, \mathrm{Mo}$ & 9 weeks ID & PR & Gastric pain, pruritus/8 & Yes & Yes & $\mathrm{P}$ & NL \\
\hline 2 & $50 / \mathrm{M}$ & 3 years & $\mathrm{L}, \mathrm{G}$ & 9 weeks ID & PR & $\begin{array}{l}\text { Poor glycemic } \\
\end{array}$ & Yes & No & - & NL \\
\hline 3 & $52 / \mathrm{M}$ & 3 weeks & $\mathrm{L}, \mathrm{A}, \mathrm{C}$ & 16 weeks ID & CR & - & No & No & - & NL \\
\hline \multirow[t]{2}{*}{4} & $56 / \mathrm{F}$ & 2 years & $\mathrm{AF}, \mathrm{SF}$ & 9 weeks ID & $\mathrm{CR}$ & - & No & Yes & S 5 months/ & WL \\
\hline & & & & 4 months DD & & & & 3 years & $\mathrm{CR}$ & \\
\hline 5 & $61 / \mathrm{M}$ & 16 years & $\mathrm{W}, \mathrm{Fe}, \mathrm{Mo}$ & 9 weeks ID & PR & Cutaneous rash $/ 8$ weeks & Yes & Yes & TE OR & $\mathrm{NL}$ \\
\hline 6 & $29 / \mathrm{M}$ & 2 years & $\mathrm{W}, \mathrm{Mo}, \mathrm{G}$ & 7 weeks ID & $\mathrm{CR}$ & - & No & Yes & S 1 year/ CR & $\mathrm{NL}$ \\
\hline 7 & $37 / \mathrm{M}$ & 3 months & $\mathrm{W}, \mathrm{A}, \mathrm{Fe}, \mathrm{C}, \mathrm{G}$ & 9 weeks ID & $\mathrm{CR}$ & Dyspepsia/8 weeks & No & Yes & No & $\mathrm{NL}$ \\
\hline \multirow[t]{2}{*}{8} & $65 / \mathrm{M}$ & 1 month & $\mathrm{L}$ & 9 weeks ID & $\mathrm{CR}$ & - & No & No & - & NL \\
\hline & & & & 5 months DD & & & & & & \\
\hline \multirow[t]{2}{*}{9} & $59 / \mathrm{F}$ & 7 months & $\mathrm{L}$ & 4 weeks ID & $\mathrm{CR}$ & - & No & No & - & $\mathrm{NL}$ \\
\hline & & & & 3 months DD & & & & & & \\
\hline \multirow[t]{2}{*}{10} & $38 / \mathrm{M}$ & 2 years & $\mathrm{W}, \mathrm{Mo}, \mathrm{G}$ & 6 weeks ID & PR & - & No & Yes & TE & WL \\
\hline & & & & 8 months DD & & & & 2 months & & \\
\hline 11 & $21 / \mathrm{F}$ & 2 weeks & $\mathrm{B}, \mathrm{Fe}, \mathrm{Mo}$ & 9 weeks ID & $\mathrm{CR}$ & - & No & No & - & NL \\
\hline \multirow[t]{2}{*}{12} & $17 / \mathrm{F}$ & 3 weeks & $\mathrm{A}, \mathrm{C}, \mathrm{B}$ & 8 weeks ID & CR & Dyspepsia/4 weeks & No & Yes & S 9 months/ & NL \\
\hline & & & & & & & & 2 months & $\mathrm{CR}$ & \\
\hline \multirow[t]{2}{*}{13} & $36 / \mathrm{F}$ & 9 years & $\mathrm{Ge}, \mathrm{Mo}$ & 9 weeks ID & $\mathrm{CR}$ & - & No & Yes & S 2 months & $\mathrm{NL}$ \\
\hline & & & & 1 year DD & & & & 3 years & Abandoned $^{\mathrm{a}}$ & \\
\hline \multirow[t]{2}{*}{14} & $22 / \mathrm{F}$ & 8 months & $\mathrm{A}, \mathrm{H}, \mathrm{L}$ & 8 weeks ID & $\mathrm{CR}$ & - & No & No & - & $\mathrm{NL}$ \\
\hline & & & & 8 weeks DD & & & & & & \\
\hline \multirow[t]{2}{*}{15} & $61 / \mathrm{M}$ & 3 weeks & $\mathrm{H}, \mathrm{L}$ & 4 weeks ID & PR & No appetite/4 weeks & No & No & - & $\mathrm{NL}$ \\
\hline & & & & 6 months DD & & & & & & \\
\hline 16 & $50 / \mathrm{M}$ & 8 months & $\mathrm{A}, \mathrm{L}$ & 16 weeks ID & $\mathrm{CR}$ & - & No & No & - & NL \\
\hline \multirow[t]{2}{*}{17} & $20 / \mathrm{F}$ & 4 months & $\mathrm{Ge}$ & 12 weeks ID & PR & Leukopenia/8 weeks & No & - & - & WL \\
\hline & & & & & & & & & & $\mathrm{S}+$ \\
\hline \multirow[t]{2}{*}{18} & $42 / \mathrm{F}$ & 2 weeks & $\mathrm{H}, \mathrm{F}, \mathrm{L}, \mathrm{B}$ & 4 weeks ID & PR & Fever/4 weeks & Yes & Yes & TE & WL \\
\hline & & & & & & & & 2 weeks & & \\
\hline 19 & $53 / \mathrm{F}$ & 4 months & $\mathrm{B}, \mathrm{W}, \mathrm{C}, \mathrm{AF}, \mathrm{IF}$ & 8 weeks ID & $\mathrm{CR}$ & - & $\mathrm{No}$ & Yes & S 4 months/CR & NL \\
\hline \multirow[t]{2}{*}{20} & $5 / \mathrm{M}$ & 3 months & $\mathrm{B}, \mathrm{C}, \mathrm{Hi}$ & 16 weeks $/ 1 \mathrm{~g} / \mathrm{d}$ & $\mathrm{CR}$ & - & No & - & - & $\mathrm{NL} \mathrm{S} \mathrm{+}$ \\
\hline & & & & 12 weeks $/ 1.25 \mathrm{~g} / \mathrm{d}$ & & & & & & \\
\hline
\end{tabular}

$\mathrm{W}=$ wrists; $\mathrm{A}=$ arms; $\mathrm{Mo}=$ mouth; $\mathrm{H}=$ hands; $\mathrm{B}=$ back; $\mathrm{AF}=$ axillar fold; IF = inguinal fold; SF = submammary fold; $\mathrm{C}=\mathrm{chest} ; \mathrm{Hi}=$ hips; $\mathrm{L}=$ legs; $\mathrm{G}=$ genitals;

$\mathrm{Ge}=$ generalized; $\mathrm{Fe}=$ feet; $\mathrm{PR}=$ partial response; $\mathrm{CR}=$ complete response; $\mathrm{M}=$ masculine; $\mathrm{F}=$ feminine; $\mathrm{g} / \mathrm{d}=$ grams/day; $\mathrm{P}=$ prednisone; $\mathrm{S}=$ sulfasalazine; TE = topical esteroids; $\mathrm{OR}=$ oral retinoids; $\mathrm{NL}=$ no lesions; $\mathrm{WL}=$ with lesions.

ID: increasing doses of $0.5 \mathrm{~g}$ per week from $1 \mathrm{~g} /$ day to $3 \mathrm{~g} /$ day.

DD: decreasing doses of $0.5 \mathrm{~g}$ every $2-4$ weeks from $3 \mathrm{~g} /$ day to $1 \mathrm{~g} /$ day depending on the clinical response.

${ }^{a}$ This patient only had side-effects when she had sulfasalazine for the second time (headache and bone pain at 2 months)

$\mathrm{S}+$ : Patient is still under treatment with sulfasalzine. 